
\section{$\varepsilon_{\mathrm{g} i \mathrm{~m}}$}

- Additional supplement data are published online only. To view this file please visit the journal online (http://dx.doi.org/ 10.1136/thoraxjnl-2012202746).

Medical Research Institute of New Zealand, Wellington,

New Zealand

\section{Correspondence to} Dr Mitesh Patel,

Medical Research Institute of New Zealand, Private Bag 7902, Wellington 6242 ,

New Zealand;

Mitesh.Patel@mrinz.ac.nz

Received 17 September 2012 Accepted 21 September 2012

CASE BASED DISCUSSION

\title{
Your asthma reliever inhaler: never leave home without it
}

\author{
Mitesh Patel, Janine Pilcher
}

\section{CHEST CLINIC}

\section{Case based discussion}

JP: A 25-year-old gentleman with asthma attended for routine out-patient review. As part of this consultation, his current symptoms and recent inhaler use were discussed, including whether he ever left home without his reliever inhaler. Though his asthma was well controlled, he reported that he always carried his reliever inhaler with him for use as a bottle opener for the treatment of acute beverage thirst attacks.

MP: Asthma patients traditionally use reliever inhalers for symptoms of chest tightness, wheeze and cough, ${ }^{1}$ and are generally advised to always keep these inhalers with them at all times. Increasing use of short-acting $\beta$-agonists for symptom relief is associated with risk of exacerbation $^{2}$ and hospital admission for asthma, ${ }^{3}$ and is an important marker of asthma control. ${ }^{4}$

There are, however, alternative uses for inhalers that are not immediately apparent to healthcare professionals. These include use to perform 'frosties', whereby the inhaler is placed close to the skin and actuated repeatedly. ${ }^{5}$

One such alternative use is as a bottle opener for the treatment of an acute beverage thirst attack. This ailment is characterised by irresistible, and often unpredictable, episodes of thirst, in the context of a busy social life. Further information from the patient is required and a diagnostic procedure is suggested.

JP: The patient was asked to simulate an acute beverage thirst attack and demonstrate his reliever inhaler technique. In keeping with recommendations, ${ }^{6} 7$ this was performed with full video monitoring. He was presented with glass bottles with non-twistable metal bottle caps.

Four demonstrations were performed using one inhaler and four beverage bottles. A total of 4/4 $(100 \%)$ attempts were successful, leading to immediate relief of the beverage thirst attack (figure 1 and online Video supplement). Mean time to successful opening (SD) was 3 (1) s and within-patient repeatability was $100 \%$. Mean bottle-top ejection height (SD) was $1(0.7) \mathrm{m}$, with some collateral loss of fluid in the process.
MP: This is the first reported case of the use of an asthma reliever inhaler to alleviate the symptoms of an acute beverage thirst attack. While traditionally used for the relief of asthma symptoms, an asthma inhaler can be indispensible in the relief of acute thirst in the context of bottle opener absence. This case provides a timely reminder regarding the importance of carrying a reliever inhaler at all times.

\section{CONSENT}

Written informed consent was obtained from the patient. The images have been anonymised.

Acknowledgements We would like to thank the patient for his participation. We are grateful to Professor Richard Beasley for his guidance.

Contributors MP and JP contributed equally to the data collection and manuscript preparation.

\section{Competing interests None.}

Patient consent Obtained

Provenance and peer review Not commissioned; internally peer reviewed.

\section{REFERENCES}

1. Ram FS, Wright J, Brocklebank D, et al. Systematic review of clinical effectiveness of pressurised metered dose inhalers versus other hand held inhaler devices for delivering beta (2) agonists bronchodilators in asthma. BMJ 2001;323:901-5.

2. Silver HS, Blanchette CM, Kamble $\mathrm{S}$, et al. Quarterly assessment of short-acting beta(2)-adrenergic agonist use as a predictor of subsequent health care use for asthmatic patients in the United States. J Asthma 2010;47:660-6.

3. Windom HH, Burgess CD, Crane J, et al. The self-administration of inhaled beta agonist drugs during severe asthma. N Z Med J 1990;103:205-7

4. SIGN/BTS. British Guideline on the Management of Asthma Thorax, 2008;63(Suppl 4):iv1-121. Revised January 2012. http://www.brit-thoracic.org.uk/ (accessed 17 Sept 2012).

5. Bonniaud P, Georges M, Blanc-Caille M, et al. Salbutamol inhaler misuse resulting in skin burn. J Allergy Clin Immunol 2011;127:295

6. Gray SL, Nance AC, Williams DM, et al. Assessment of interrater and intrarater reliability in the evaluation of metered dose inhaler technique. Chest 1994;105:710-14

7. Rootmensen GN, van Keimpema AR, Looysen EE, et al. Reliability in the assessment of videotaped inhalation technique. J Aerosol Med 2007;20:429-433.

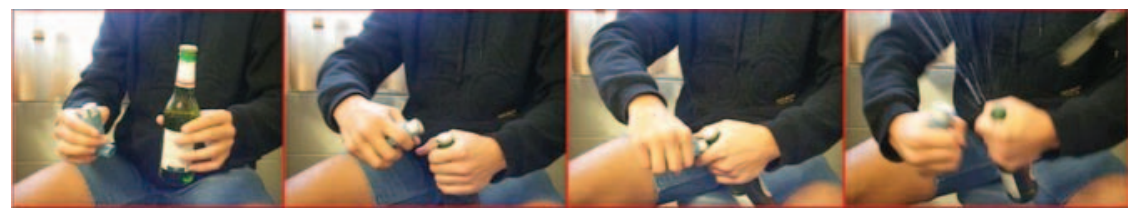

Figure 1 Bottle opening during a simulated acute beverage thirst attack. 